\title{
Personality and the Genetic Risk for Alcohol Dependence
}

\author{
Wendy S. Slutske \\ University of Missouri-Columbia
}

\author{
Andrew C. Heath, Pamela A. F. Madden, \\ and Kathleen K. Bucholz \\ Washington University School of Medicine
}

\author{
Dixie J. Statham and Nicholas G. Martin \\ Queensland Institute of Medical Research
}

\begin{abstract}
The extent to which the genetic risk for alcohol dependence (AD) and conduct disorder (CD) and their common genetic risk overlap with genetic factors contributing to variation in dimensions of personality was examined in a study of 6,453 individuals from 3,383 adult male and female same-sex and unlike-sex twin pairs from the Australian Twin Registry. The associations between the personality dimensions of positive emotionality, negative emotionality, and $A D$ and $C D$ risk were modest, whereas the associations between behavioral undercontrol and $A D$ and $C D$ risk were substantially higher. Genetic influences contributing to variation in behavioral undercontrol accounted for about $40 \%$ of the genetic variation in $A D$ and $C D$ risk and about $90 \%$ of the common genetic risk for $A D$ and $C D$. These results suggest that genetic factors contributing to variation in dimensions of personality, particularly behavioral undercontrol, account for a substantial proportion of the genetic diathesis for AD and most of the common genetic diathesis for $\mathrm{AD}$ and $\mathrm{CD}$ among both men and women.
\end{abstract}

Several theories of the etiology of alcoholism posit that the genetic diathesis for alcoholism is partially mediated by temperament or personality (Cloninger, 1987a; Tarter, 1988; Tarter, Alterman, \& Edwards, 1985; Zuckerman, 1987). There are several lines of evidence that indirectly support this proposition. First, genetic factors have been consistently implicated in contributing to

Wendy S. Slutske, Department of Psychological Sciences and Missouri Alcoholism Research Center, University of Missouri-Columbia; Andrew C. Heath, Pamela A. F. Madden, and Kathleen K. Bucholz, Department of Psychiatry and Missouri Alcoholism Research Center, Washington University School of Medicine; Dixie J. Statham and Nicholas G. Martin, Epidemiology Unit, Queensland Institute of Medical Research, Brisbane, Queensland, Australia.

This work was supported by the National Institutes of Health (Grants AA00264, AA07535, AA07728, and AA10249 and Postdoctoral Training Grants MH17104 and DA07261), by a grant from the Australian National Health and Medical Research Council, and by the Missouri Alcoholism Research Center, University of Missouri-Columbia and Washington University School of Medicine (Grant AA11998). Portions of this research were presented at the 28th Annual Meeting of the Behavior Genetics Association, Stockholm, Sweden, June 1998, and at the 107th Annual Convention of the American Psychological Association, Boston, Massachusetts, August 1999.

We acknowledge the assistance of Randy Cates, Michael Hodge, Sue Mason, Hui Pan, Theresa Pangan, John Pearson, Pamela Saunders, Olivia Zheng, and the interviewers. We thank the twins from the Australian National Health and Medical Research Council Twin Registry for their continuing cooperation.

Correspondence, concerning this article should be addressed to Wendy S. Slutske, Department of Psychological Sciences, University of Missouri, 210 McAlester Hall, Columbia, Missouri 65211. E-mail: SlutskeW@ missouri.edu individual differences in personality traits, with about one third to one half of the variation in personality typically being attributed to such factors (Eaves, Eysenck, \& Martin, 1989; Loehlin, 1992). Second, cross-sectional studies consistently show associations of several personality traits with a history of alcoholism (McGue, Slutske, Taylor, \& lacono, 1997; Sher \& Trull, 1994; Sher, Trull, Bartholow, \& Vieth, 1999), and longitudinal studies provide evidence that at least some of these personality correlates are developmental antecedents of alcoholism (Caspi et al., 1997; Cloninger, Sigvardsson, \& Bohman, 1988; Loper, Kammeier, \& Hoffman, 1973; Zucker \& Lisansky Gomberg, 1986). Specifically, the traits of impulsivity, thrill seeking, rebelliousness, nonconformity, and aggressiveness (i.e., "behavioral undercontrol"; Sher, 1991) are robust predictors of alcoholism. Third, studies of the offspring of alcoholics suggest that the personality traits of behavioral undercontrol may be related to the familial diathesis underlying alcoholism risk (e.g., Finn, Sharkansky, Brandt, \& Turcotte, 2000; Sher, Walitzer, Wood, \& Brent, 1991). However, family studies cannot disentangle the extent to which personality traits are related to the genetic versus environmental risk for alcoholism.

In this study, we examined the extent to which genetic factors contributing to variation in dimensions of personality are associated with genetic susceptibility for alcohol dependence (AD). Previously, we showed that most of the overlap between AD and conduct disorder (CD) could be accounted for by common genetic risk factors (Slutske et al., 1998). Because AD and CD share many of the same personality correlates and predictors (Krueger, Caspi, \& Moffitt, 2000; Sher \& Trull, 1994), we also examined and quantified in the present study the extent to which the risk for CD and the common genetic risk for AD and CD overlap with genetic factors contributing to variation in dimensions of personality. 
Method

\section{Participants}

The participants were members of the Australian National Health and Medical Research Council Twin Registry (ATR), a national volunteer twin panel recruited through the media, schools, and a variety of other sources (Jardine \& Martin, 1984). We analyzed data obtained from a 1988 questionnaire survey $(N=6,327 ; 83 \%$ overall individual response rate; see Heath, Cloninger, \& Martin, 1994, for details) and a 1992 telephone interview survey $(N=5,889 ; 86 \%$ overall individual response rate; sec Heath, Bucholz, et al., 1997, for details). Mean ages at interview were $\mathbf{4 2 . 7}$ years for men (range $=28-89$ years) and 44.8 years for women (range $=$ 27-90 years; see Heath, Bucholz, et al., 1997; Slutske et al., 1997; or Slutske et al., 1998, for further details about response rates, attrition, and the representativeness of the ATR sample).

One set of analyses in the present study ("complete-data" analyses) was based on twin pairs for whom there were complete data on personality from the 1988 questionnaire and complete data on psychopathology from the 1992 interview (see the shaded portion of Figure 1). There were 2,261 such twin pairs ( 818 female monozygotic [MZ] pairs, 338 male MZ pairs, 445 female-female dizygotic [DZ] pairs, 183 male-male $D Z$ pairs, and 477 female-male DZ pairs). Another set of analyses ("all-data" analyses) involved all available data, including data from twins whose co-twin did not participate or who provided only questionnaire or only interview data. There were 3,383 twin pairs (1,097 female MZ pairs, 506 male $M Z$ pairs, 667 female-female DZ pairs, 320 male-male DZ pairs, and 793 femalemale $D Z$ pairs) in which either questionnaire or interview data were available for at least one twin (see Figure 1).

\section{Measures}

Zygosity. Twin zygosity diagnoses were mainly based on questionnaire responses concerning physical similarity and how often the twins were mistaken for each other as children. This method of zygosity diag. nosis has been shown to be about $95 \%$ accurate, as validated against blood typing (Eaves et al., 1989). In addition, pairs in which zygosity was ambiguous or there was disagreement between co-twins were followed up for further information, and in many cases twins were asked to provide photographs to assist in assigning zygosity. There was perfect agreement between the final zygosity diagnoses and zygosity assignment based on eight DNA microsatellite markers for 190 same-sex twin pairs from the present study (Duffy, 1994).

Personality. A 54-item short form of the Tridimensional Personality Questionnaire (TPQ; Cloninger, Przybeck, \& Svrakic, 1991) and a 48-item short form of the Eysenck Personality Questionnaire (EPQ-R; Eysenck, Eysenck, \& Barrett, 1985) were assessed in 1988 through a mailed questionnaire. The TPQ responses yielded Novelty Seeking, Harm Avoidance. and Reward Dependence scores (Cloninger, 1987a, 1987b), and responses to the EPQ-R items yielded Extraversion, Neuroticism, Psychoticism, and (reverse-scored) Lie scores.

Three higher order personality dimensions were created on the basis of the results of a principal-components analysis of the seven scales of the TPQ and EPQ-R. Initial factor extraction yielded three factors with eigenvalues greater than one that explained $70 \%$ of the total variance among the seven scales. We labeled one personality dimension "positive emotionality" (PE; the sum of TPQ reward dependence and EPQ-R extraversion scores, accounting for $18 \%$ of the total variance); high scorers on the PE

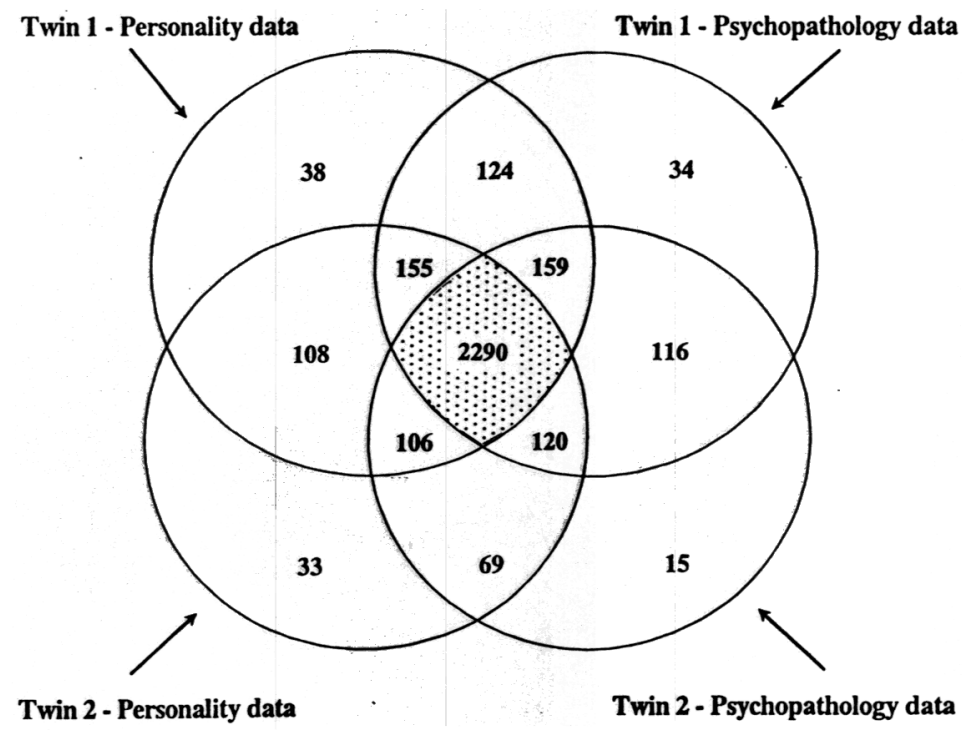

Figure 1. Simplified schematic of the frequency of each combination of missing data among 3,367 of 3,383 twin pairs. Two combinations of missing data accounting for 16 additional twin pairs are not shown: 8 twin pairs in which only personality data were available for Twin 1 and only psychopathology data were available for Twin 2, and 8 twin pairs in which only personality data were available for Twin 2 and only psychopathology data were available for Twin 1. Also not shown are combinations of missing data within each category represented (e.e.. missing scores for positive emotionality but scores available for neqative emotionality and behavioral undercontrol). "Complete-data" twin pair analyses were based on data from 2,261 twin pairs (of the 2,290 represented in the central shaded portion of the schematic) in which both twins had complete personality (scores for positive emotionality, negative emotionality, and behavioral undercontrol) and psychopathology (diagnoses of alcohol dependence and conduct disorder) data. "All-data" twin pair analyses were based on available data from all 3,367 iwin pairs represented in the schematic, along with the 16 additional pairs not shown (a total of 3,383 twin pairs). 
dimension are outgoing, lively, persistent, and warm. We labeled another personality dimension "negative emotionality" (NE; the sum of TPQ Harm Avoidance and EPQ-R Neuroticism, accounting for $31 \%$ of the total variance); high scorers on the NE dimension are anxious, inhibited, moody, and unhappy. We labeled the third personality dimension behavioral undercontrol (BU; the sum of TPQ Novelty Seeking, EPQ-R Psychoticism, and EPQ-R reverse-scored Lie, accounting for $21 \%$ of the total variance); high scorers on the BU dimension are impulsive, thrill seeking, irresponsible, and rebellious. These three personality dimensions are similar to the sociability, emotionality, and impulsive-unsocialized sensation-seeking dimensions that Zuckerman, Kuhlman, and Camac (1988) obtained in a factor analysis of 46 personality scales and to other "Big Three" conceptualizations of personality structure (Zuckerman, Kuhlman, Joireman, Teta, \& Kraft, 1993). Alpha coefficients were .82 for PE, .90 for NE, and .67 for BU. The 2-year stabilities among 869 individuals from the present study were .83 for PE, .84 for NE, and .81 for BU. Scores on the three dimensions were polychotomized into six ordinal categories for all of the analyses.

$C D$. The Semi-Structured Assessment for the Genetics of Alcoholism (SSAGA) interview (Bucholz et al., 1994), originally developed for the Collaborative Study on the Genetics of Alcoholism, was abridged to cover only the Diagnostic and Statistical Manual of Mental Disorders (revised third edition; DSM-III-R; American Psychiatric Association, 1987) and was modified for use as a telephone interview in Australia (SSAGA-OZ). Interviews were administered by trained lay interviewers who were unaware of the psychiatric status of the co-twin. Interviewers were supervised by a projoct coordinator, a qualifical clinical poyclivlugist will 4 years of experience. All interview protocols were reviewed either by the project coordinator or by the most skilled interviewers (those who maintained consistently low error rates in coding); the reviews were always done by someone other than the person who conducted the interview. In addition, all interviews were tape-recorded, and a random $5 \%$ of interview tapes were reviewed for quality control and coding inconsistencies.

Individual CD symptoms were assessed by telephone interview with the SSAGA-OZ. The individual CD symptoms were aggregated into lifetime CD diagnoses by computer algorithm according to $D S M-I I I-R$ criteria (endorsement of three or more CD symptoms occurring before the age of 18 years). Lifetime prevalence rates of $C D$ in this sample were $18 \%$ in men and $3 \%$ in women. The long-term interrater test-retest reliability of these retrospective lifetime diagnoses of childhood $\mathrm{CD}$ over a 15-month interval was good ( $\kappa=.39$, Yules $Y=.68$, tetrachoric $r=.78$; Slutske et al., 1997).

$A D$. Individual symptoms of $\mathrm{AD}$ were assessed by telephone interview and aggregated into lifetime $D S M-I I I-R$ diagnoses by computer algorithm. The $D S M-I I I-R$ definition yielded lifetime AD prevalence rates in this sample of $23 \%$ among men and $5 \%$ among women. The long-term interrater test-retest reliability of these retrospective lifetime diagnoses over a $1-3$-year interval was also good $(\kappa=.52$, Yules $Y=.65$, tetrachoric $r=$ .79; Heath, Bucholz, et al., 1997).

Although the measures of personality were obtained roughly 4 years before the assessment of $A D$ and $C D$, this study is best viewed as crosssectional rather than longitudinal. Both $A D$ and $C D$ were based on retrospective reports, and many of the problems reported (most of the AD and all of the $\mathrm{CD}$ ) would have occurred before the personality assessment.

\section{Data Analysis}

Before twin model fitting, polychoric correlations of $\mathrm{AD}$ and $\mathrm{CD}$ with $\mathrm{PE}, \mathrm{NE}$, and $\mathrm{BU}$ were estimated, and differences between correlations were tested with structural equation models in Mx (Neale, Boker, Xie, \& Maes, 1999) that accounted for the twin structure of the data. Two methods of twin structural equation model fitting were used. "Complete-data" analyses required complete data for all measures from both twin pairs and so involved only a subset of the available data. In these analyses, matrices of polychoric correlations for each of the five groups (i.e., female $M Z$, male $M Z$, female-female DZ, male-male DZ, and female-male DZ) were generated by the method of maximum likelihood using PRELIS (Jöreskog \& Sörbom, 1996). Models were fitted to the five twin correlation matrices and corresponding asymptotic covariance weight matrices by the method of weighted least squares with the Mx program (Neale et al., 1999). All-data analyses involved all of the available data from 3,383 twin pairs. In these analyses, models were fitted directly to the raw ordinal data by the method of maximum likelihood with the Mx program (Neale et al., 1999).

Each of the two model-fitting methods has advantages and disadvantages. The advantage of the complete-data method is that it is computationally very efficient. Models can be fitted in a matter of minutes, and so it is feasible, for example, to refit models using different starting values to check the correctness of obtained solutions and to test various hypotheses about the significance of or the equivalence of parameters in a model. The disadvantage of the complete-data method is that many of the available data are wasted (in this study, data from 1,122 twin pairs with incomplete information were discarded). If there are biases due to attrition or nonparticipation because the data are not missing completely at random (Little \& Rubin, 1987), complete-data analyses may lead to incorrect conclusions.

The advantage of the all-data model-fitting method is that it can correct for biases due to attrition and nonparticipation when data are missing at random (Little \& Rubin, 1987). Because more of the data are used, parameter estimates are more precise and confidence intervals (CIs) are usually narrower. The only disadvantage of the all-data method is that it is extremely computationally intensive, and models with more than two or three categorical variables are beyond the limits of available computing power. We chose to take advantage of the complementary strengths of the two model-fitting methods. In the process, we were able to indirectly assess potential biases in the sample by comparing the results obtained with the two methods. The results were quite similar for most analyses.

All of the parameters of interest were estimated within reduced biometric structural equation models that partitioned the variation in liability and the sources of covariation in liability into that due to additive genetic and nonshared environmental influences. Because the aims of this study were to quantify the extent to which genetic factors contributing to variation in personality dimensions are associated with genetic variation in the risk for $\mathrm{AD}$ and $\mathrm{CD}$ and to quantify the extent to which genetic factors contributing to variation in personality dimensions overlap with the genetic sources of covariation between $A D$ and $C D$, we focused on the results of reduced models to simplify the presentation. For none of the five variables studied (AD, CD, PE, NE, and BU) did estimates of shared family environmental factors differ significantly from zero, whereas genetic influences were significant for all (see Heath, Bucholz, et al., 1997; Heath et al., 1994; Slutske et al., 1997). For example, when shared family environmental factors were included in models, they accounted for only $1.8 \%$ of the total variation, on average, in the personality dimensions (range $=0 \%-12 \%$ ). Thus, the results for the genetic associations between personality dimensions and $A D$ and $C D$ were not altered substantially when shared family environmental factors were omitted from models relative to when they were included.

Figure 2 illustrates the trivariate Cholesky model (Loehlin, 1996) that was fitted to quantify the extent to which the genetic covariation between $\mathrm{AD}$ and $\mathrm{CD}$ is determined by genetic factors that also influence BU. For simplicity, the model for a single individual rather than a twin pair is illustrated. In this model, factors $A_{1}$ and $E_{1}$ account for all of the additive genetic and nonshared environmental variation in the risk for $\mathrm{BU}$ and any of the variation in the risk for $\mathrm{CD}$ and $\mathrm{AD}$ that is in common with the risk for $B U$. Factors $A_{2}$ and $E_{2}$ account for any residual additive genetic and nonshared environmental variation in the risk for $\mathrm{CD}$ (after accounting for the variation in $C D$ risk that is shared with $B U$ ) and any residual variation in the risk for $A D$ that is in common with the risk for $C D$. Factors $A_{3}$ and $E_{3}$ account for any residual additive genetic and nonshared environmental variation in the risk for $A D$ (after accounting for the variation in $A D$ risk 


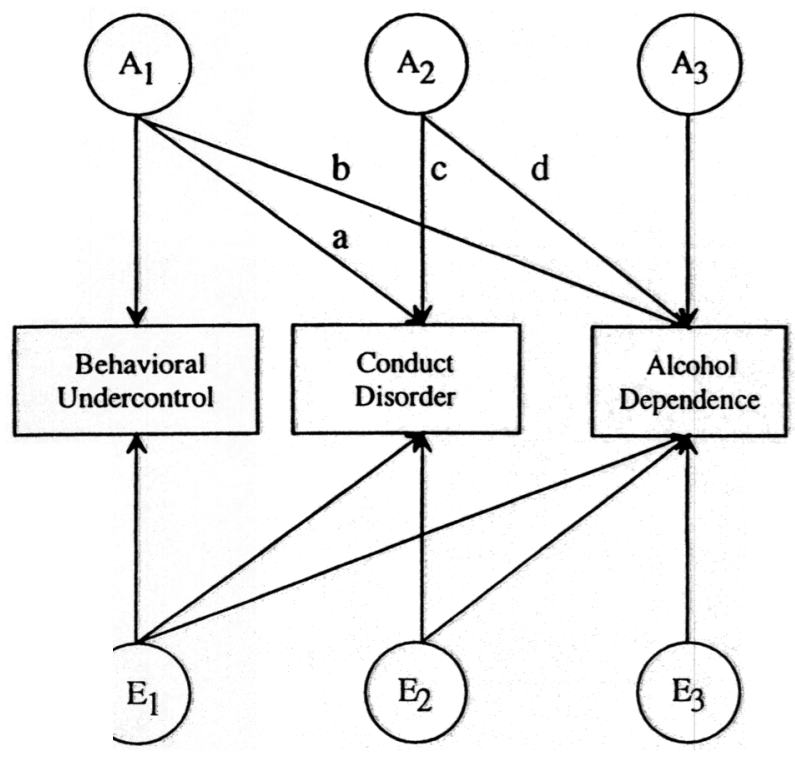

Figure 2. A model, illustrated for a single individual from a twin pair, for quantifying the extent to which behavioral undercontrol $(\mathrm{BU})$ mediates the genetic covariation between alcohol dependence (AD) and conduct disorder (CD). Factors $A_{1}$ and $E_{1}$ account for all of the additive genetic and nonshared environmental variation in the risk for $\mathrm{BU}$ and any of the variation in the risk for $C D$ and $A D$ that is in common with the risk for $B U$. Factors $A_{2}$ and $E_{2}$ account for any residual additive genetic and nonshared environmental variation in the risk for $C D$ (after accounting for the variation in $C D$ risk that is shared with $B U$ ) and any residual variation in the risk for $A D$ that is in common with the risk for $C D$. Factors $A_{3}$ and $E_{3}$ account for anv residual additive genetic and nonshared environmental variation in the risk for $\mathrm{AD}$ (after accounting for the variation in $\mathrm{AD}$ risk that is shared with $B U$ and $C D$ ). The proportion of genetic covariation between $A D$ and $C D$ attributable to $B U$ is $(a \times b) /(a \times b+c \times d)$.

that is shared with $\mathrm{BU}$ or $\mathrm{CD}$ ). The Cholesky model is conceptually similar to a principal-components or hierarchical multiple regression analysis.

The total genetic covariation between AD and $\mathrm{CD}$ is the sum of pathways $a \times b$ and $c \times d$, and the portion that is accounted for by genetic variation in $B U$ is represented by the pathway $\mathbf{a} \times \mathbf{b}$. Thus, the proportion of genetic covariation between $A D$ and $C D$ attributable to $B U$ is ( $X$ b) $/(a \times b+c \times d)$. Similar models were used to estimate genetic correlations among $\mathrm{AD}, \mathrm{CD}$, and personality dimensions and to estimate the proportion of variation in $\mathrm{AD}$ or $\mathrm{CD}$ risk accounted for by other personality dimensions (see Carey \& DiLalla, 1994; Neale \& Cardon, 1992; or Slutske et al., 1998, for more details about multivariate twin model fitting).

In some cases there were significant differences in parameter estimates for men and women, and in other cases estimates for men and women could be constrained without a significant decrement in model fit. For this reason, we elected to report parameter estimates separately for men and women as well as estimates from analyses combining men and women. Combined estimates were obtained by constraining estimates of parameters of interest to be equal in men and women while allowing thresholds (i.e., prevalences) to differ.

\section{Results}

\section{Associations of $A D$ and $C D$ With Personality Dimensions}

The correlations between $\mathrm{AD}$ and $\mathrm{CD}$ were .33 and .63 among men and women, respectively, when "complete data" were used and .34 and .53 , respectively, when "all data" were used; these correlations are similar to previously reported estimates (Slutske et al., 1998). The correlations of $\mathrm{AD}$ and $\mathrm{CD}$ with the personality dimensions were very similar in the complete-data analyses and the all-data analyses; the mean difference between the correlations estimated with the two methods was .03 (range $=.00-.06$ ). Results of the all-data analyses are presented in Table 1. With only a few exceptions, the personality correlates of $\mathrm{AD}$ were the same as the personality correlates of $\mathrm{CD}$. BU was strongly and significantly associated with $\mathrm{AD}$ and $\mathrm{CD}$ in both men and women. PE was significantly associated with $\mathrm{CD}$ in both men and women but was significantly associated with AD only among women. Although PE was significantly associated with $C D$ in both sexes, the association among women was significantly larger than that among men (complete data), $\chi^{2}(1)=4.57, p=.03$. NE was associated only with $\mathrm{AD}$, and this association was found only among men.

\section{Twin Model Fitting of the Associations of $A D$ and $C D$ With Personality Dimensions}

Before fitting multivariate models to the twin data, we examined the proportion of variation attributed to genetic factors for each of the variables in univariate models. The heritabilities for $A D, C D$, and the three personality dimensions were very similar in the complete-data analyses and the all-data analyses; the mean difference between the heritabilities estimated with the two methods was .02 (range $=.00-.06$ ). Results of the all-data analyses are presented in Table 2. The heritabilities for the personality dimensions were moderate, with genetic factors accounting for one third to one half of the variation, and the horitabilitioc for $A D$ and $C D$ wore relatively high, with genetic factors accounting for approximately two thirds of the variation in risk. The heritabilities for $A D, C D$, and PE did not significantly differ for men and women, but the heritabilities for NE and BU were significantly higher among women than among men (complete data), $\mathrm{NE} \chi^{2}(1)=5.61, p=$ .02 , and $\mathrm{BU} \chi^{2}(1)=6.91, p=.01$.

Genetic factors contributing to variation in dimensions of personality were significantly correlated with genetic susceptibility for $\mathrm{AD}$ and $\mathrm{CD}$. The genetic correlations of $\mathrm{AD}$ and $\mathrm{CD}$ with the three personality dimensions were very similar in the complete-

Table 1

Correlations Between Personality Dimensions and Lifetime Histories of Alcohol Dependence and Childhood Conduct Disorder Among Adult Men and Women

\begin{tabular}{|c|c|c|c|c|c|c|}
\hline \multirow{2}{*}{$\begin{array}{c}\text { Personality } \\
\text { dimension }\end{array}$} & \multicolumn{3}{|c|}{ Alcohol dependence } & \multicolumn{3}{|c|}{ Conduct disorder } \\
\hline & Men & Women & Comḅined & Men & Women & Combined \\
\hline $\begin{array}{l}\text { Positive } \\
\text { emotionality }\end{array}$ & .03 & $.18^{\mathrm{a}}$ & $12^{\mathrm{a}}$ & $.10^{\mathrm{a}}$ & $.21^{\mathrm{a}}$ & $.13^{\mathrm{a}}$ \\
\hline $\begin{array}{l}\text { Negative } \\
\text { emotionality } \\
\text { Deliaviunal }\end{array}$ & $.20^{\mathrm{a}}$ & .05 & $.11^{*}$ & .05 & .07 & .06 \\
\hline undercontrol & $.38^{\mathrm{a}}$ & $.38^{\mathrm{a}}$ & $.38^{\mathrm{a}}$ & $.49^{a}$ & $.49^{\mathrm{a}}$ & $.50^{\mathrm{a}}$ \\
\hline
\end{tabular}

Note. $N=6,453$ (some with missing data).

${ }^{2}$ Correlation significantly differs from zero at $p<.01$; all correlations without superscripts failed to meet the $p<.05$ level of statistical significance. 
Table 2

Estimates of the Proportions of Variation in Risk Attributed to Additive Genetic Factors From Reduced Univariate Twin Models of Personality, Conduct Disorder, and Alcohol Dependence

\begin{tabular}{|c|c|c|c|c|c|c|}
\hline \multirow[b]{2}{*}{ Dimension or disorder } & \multicolumn{2}{|c|}{ Men } & \multicolumn{2}{|c|}{ Women } & \multicolumn{2}{|c|}{ Combined } \\
\hline & Estimate & $95 \% \mathrm{CI}$ & Estimate & 95\% CI & Estimate & $95 \% \mathrm{CI}$ \\
\hline Positive emotionality & .48 & $.40-.56$ & .47 & $.41-.52$ & .47 & $.43-.51$ \\
\hline Negative emotionality & .33 & $.23-.43$ & .48 & $.43-.53$ & .44 & $.40-.49$ \\
\hline Behavioral undercontrol & .43 & $.34-.50$ & .55 & $.50-.59$ & .51 & $.47-.55$ \\
\hline Conduct disorder & .69 & $.56-.80$ & .69 & $.48-.84$ & .69 & $.58-.78$ \\
\hline Alcohol dependence & .67 & $.54-.77$ & .60 & $.44-.73$ & .63 & $.54-.72$ \\
\hline
\end{tabular}

Note. Reduced models included additive genetic and nonshared environmental factors. $N=6,453$ individuals from 3,383 twin pairs, some with missing data. $\mathrm{CI}=$ confidence interval.

data analyses and the all-data analyses; the mean difference between the genetic correlations estimated with the two methods was .04 (range $=.00-.10$ ). Results of the all-data analyses are presented in Table 3 . There were significant genetic correlations of PE with $A D$ and $C D$ and significant correlations of $B U$ with $A D$ and $\mathrm{CD}$ among both men and women. The only significant genetic correlation involving $\mathrm{NE}$ was in the case of $\mathrm{AD}$ among men. The genetic correlation between $\mathrm{NE}$ and $\mathrm{AD}$ was significantly larger among men than among women (complete data), $\chi^{2}(1)=5.28$, $p=.02$, and the genetic correlation between $\mathrm{BU}$ and $\mathrm{AD}$ was significantly larger among women than among men (complete data), $\chi^{2}(1)=6.09, p=.01$. None of the other genetic correlations differed significantly between men and women.

The observed correlations between personality dimensions and AD roported in Table 1 were mostly duc to commun zenctic influences. Common genetic factors accounted for $100 \%$ of the correlation between $\mathrm{PE}$ and $\mathrm{AD}, 56 \%$ of the correlation between $\mathrm{NE}$ and $\mathrm{AD}$ among men (NE and $\mathrm{AD}$ were uncorrelated among women), and $91 \%$ of the correlation between $\mathrm{BU}$ and $\mathrm{AD}$. These results were largely unchanged when shared family environmental factors were included in models. After inclusion of these factors, common genetic factors accounted for $100 \%$ of the correlation between $\mathrm{PE}$ and $\mathrm{AD}, 51 \%$ of the correlation between NE and $\mathrm{AD}$ among men, and $90 \%$ of the correlation between $\mathrm{BU}$ and $\mathrm{AD}$. Similarly, common genetic factors accounted for $98 \%$ of the correlation between PE and CD ( $98 \%$ when shared family environmental influences were included in the model) and $70 \%$ of the correlation between BU and CD (60\% when shared family environmental influences were included in the model). Because NE and $C D$ were uncorrelated in both men and women, we did not examine the extent to which genetic factors accounted for their association.

The personality dimensions of $\mathrm{PE}, \mathrm{NE}$, and $\mathrm{BU}$ accounted for $3 \%-13 \%, 0 \%-4 \%$, and $28 \%-49 \%$ of the genetic variation in $\mathrm{AD}$ risk, respectively, and $3 \%-10 \%, 0 \%$, and $35 \%-45 \%$ of the genetic variation in CD risk, respectively (see Table 4). We examined the extent to which the contributions of these three personality dimensions were additive or overlapping by including PE and NE in madels that included BU and tocting whother they oontributod incremental variation in genetic risk for $A D$ or $C D$. After controlling for variation accounted for by BU, PE did not account for any additional genetic variation in $\mathrm{AD}$ and $\mathrm{CD}$ risk for men (complete data), $\chi^{2}(1)=0.54, p=.46$, and $\chi^{2}(1)=0.75, p=.39$, respectively, or women (complete data), $\chi^{2}(1)=0.52, p=.47$, and $\chi^{2}(1)=2.46, p=.12$, respectively. However, NE accounted for additional genetic variation in $\mathrm{AD}$ risk after controlling for variation accounted for by $\mathrm{BU}$ among men (complete data), $\chi^{2}(1)=5.19, p=.02$, although the increment in genetic variation accounted for was modest $(4 \%)$.

\section{Personality and Common Genetic Risk for $A D$ and $C D$}

In our previous study (Slutske et al., 1998), we used data from 2,682 twin pairs with complete interview data and obtained estimates of the genetic correlation between $\mathrm{AD}$ and $\mathrm{CD}$ of .41 $(95 \% \mathrm{CI}=.27-.56)$ for men and $.59(95 \% \mathrm{CI}=.40-.78)$ for women. Using complete data from 2,261 twin pairs in the present study, we obtained estimates of the genetic correlation between $A D$ and $C D$ of unly .19 (95 $\pi \mathrm{CI}-.05-.34)$ fun uncu allu .40 (95\% $\mathrm{CI}=.16-.63$ ) for women; using all data from 3,383 twin pairs, we obtained more similar estimates of $.37(95 \% \mathrm{CI}=.22-.53)$ for men and $.49(95 \% \mathrm{CI}=.25-.71)$ for women. Although the $95 \%$ CIs around estimates overlapped for all three sets of analyses, the estimate of the genetic correlation between $\mathrm{AD}$ and $\mathrm{CD}$ among men in complete-data analyses was substantially lower than was obtained in all-data analyses.

The proportions of genetic covariation between $\mathrm{AD}$ and $\mathrm{CD}$ accounted for by the three personality dimensions of $\mathrm{PE}, \mathrm{NE}$, and BU were very similar in the complete-data analyses and the all-data analyses; the mean difference between the proportions estimated with the two methods was .03 (range $=.00-.15$ ). Results of the all-data analyses are presented in Table 5. PE accounted for a modest but significant proportion of the genetic covariation between $A D$ and $C D$ (but not after controlling for genetic covariation accounted for by BU), NE did not account for any of the genetic covariation, and $\mathrm{BU}$ accounted for a substantial and significant proportion of the genetic covariation between $A D$ and $C D$ in both men and women. The hypothesis that BU accounted for all of the genetic covariation between $\mathrm{AD}$ and $\mathrm{CD}$ could not be rejected. The proportion of genetic covariation between $\mathrm{AD}$ and $\mathrm{CD}$ accounted for by PE, NE, or BU did not differ significantly between men and women.

\section{Probing the Associations Between $A D$ and $C D$ and the Components of $\mathrm{BU}$}

Because BU was the personality dimension most strongly associated with genetic risk for $A D$ and $C D$, and because it appeared 
Table 3

Genetic Correlations Between Personality Dimensions and Lifetime Histories of Alcohol Dependence and Childhood Conduct Disorder Among Adult Men and Women

\begin{tabular}{|c|c|c|c|c|c|c|c|c|c|c|c|c|}
\hline \multirow[b]{3}{*}{ Personality dinension } & \multicolumn{6}{|c|}{ Alcohol dependence } & \multicolumn{6}{|c|}{ Conduct disorder } \\
\hline & \multicolumn{2}{|c|}{ Men } & \multicolumn{2}{|c|}{ Women } & \multicolumn{2}{|c|}{ Conbined } & \multicolumn{2}{|c|}{ Men } & \multicolumn{2}{|c|}{ Women } & \multicolumn{2}{|c|}{ Combined } \\
\hline & Estimate & $95 \% \mathrm{CI}$ & Estimate & $95 \% \mathrm{Cl}$ & Estimate & $95 \% \mathrm{Cl}$ & Estimate & $95 \% \mathrm{Cl}$ & Estimate & $95 \% \mathrm{Cl}$ & Estimate & $95 \% \mathrm{CI}$ \\
\hline Positive emotiorality & .18 & $02-.34$ & .36 & $.19-.53$ & .26 & $.14-.38$ & 16 & $.01-.32$ & .31 & $.10-.52$ & 22 & $.09-.35$ \\
\hline Negative emoticnality & .21 & $02-.39$ & -.06 & $-.23-.10$ & .06 & $-.06-.18$ & 01 & $.19-.20$ & .07 & $-.14-.27$ & 03 & $-.10-.17$ \\
\hline Behavioral undercontrol & .53 & $38-.67$ & .71 & $.56-.86$ & .61 & $.51-.72$ & 59 & $.45-.72$ & .67 & $.50-.85$ & 61 & $.51-.71$ \\
\hline
\end{tabular}

Note. Estimates are from reduced models that included additive genetic and nonshared environmental factors. $N=6,453$ individuals from 3,383 twin pairs, some with missing data. $\mathrm{Cl}=$ confidence interval.

Table 4

Proportions of Genetic Variation in Alcohol Dependence and Conduct Disorder Risk Accounted for by Genetic Factors That Also Influenced the Assessed Personality Dimensions

\begin{tabular}{|c|c|c|c|c|c|c|c|c|c|c|c|c|}
\hline \multirow[b]{3}{*}{ Personality dinension } & \multicolumn{6}{|c|}{ Alcohol dependence } & \multicolumn{6}{|c|}{ Conduct disorder } \\
\hline & \multicolumn{2}{|c|}{ Men } & \multicolumn{2}{|c|}{ Women } & \multicolumn{2}{|c|}{ Combined } & \multicolumn{2}{|c|}{ Men } & \multicolumn{2}{|c|}{ Women } & \multicolumn{2}{|c|}{ Combined } \\
\hline & Estimate & $95 \% \mathrm{Cl}$ & Estimate & $95 \% \mathrm{CI}$ & Estimate & $95 \% \mathrm{CI}$ & Estimate & $95 \% \mathrm{CI}$ & Estimate & $95 \% \mathrm{CI}$ & Estimate & $95 \% \mathrm{CI}$ \\
\hline Positive emotiolality & 03 & $.001-.12$ & .13 & $.04-28$ & .07 & $.02-.14$ & .03 & $001-.10$ & .10 & $.01-.27$ & .05 & $01-.12$ \\
\hline Negative emotionality & 04 & $.001-.15$ & .00 & $.00-.05$ & .00 & $.00-.03$ & .00 & $.00-.04$ & .00 & $.00-.07$ & .00 & $00-.03$ \\
\hline Behavioral undercontrol & 28 & $.14-.45$ & .49 & $.31-.74$ & .37 & $.26-.52$ & .35 & $.20-.52$ & .45 & $.25-.72$ & 37 & $26-.50$ \\
\hline
\end{tabular}

Note. Estimats are from reduced models that included additive genetic and nonshared environnental factors. $N=6,453$ individuals from 3,383 twin pairs, some with missing data. $\mathrm{CI}=$ confidence interval. 
Table 5

Proportions of Genetic Covariation Between Alcohol Dependence and Conduct Disorder Risk Accounted for by Genetic Factors That Also Influenced the Assessed Personality Dimensions

\begin{tabular}{ccccccccc}
\hline & \multicolumn{2}{c}{ Men } & & \multicolumn{2}{c}{ Women } & & \multicolumn{2}{c}{ Combined } \\
\cline { 2 - 3 } Personality dimension & Estimate & $95 \% \mathrm{CI}$ & & Estimate & $95 \% \mathrm{CI}$ & & Estimate & $95 \% \mathrm{CI}$ \\
\hline & .08 & $.01-.24$ & .22 & $.07-.60$ & & .13 & $.05-.29$ \\
& .00 & $.00-15$ & & .00 & $.00-.02$ & & .00 & $.00-.04$ \\
& .85 & $.54-1.00$ & & .93 & $.59-1.00$ & & .88 & $.64-1.00$ \\
\hline
\end{tabular}

Note. Estimates are from reduced models that included additive genetic and nonshared environmental factors. $N=6,453$ individuals from 3,383 twin pairs, some with missing data. $\mathrm{CI}=$ confidence interval.

to be a more heterogeneous construct than the other two dimensions, we conducted a supplementary set of complete-data analyses of the three component scales of BU (i.e., TPQ Novelty Seeking, EPQ-R Psychoticism, and EPQ-R reverse-scored Lie). Item-level factor analyses revealed that the three highest loading items of Novelty seeking were similar in that they were strong markers of the BU component of impulsivity (highest loading item [scored false]: "I usually think about all of the facts in detail before I make a decision"). The two highest loading items of Psychoticism were strong markers of the BU component of rebelliousness or social nonconformity (highest loading item: "Do you prefer to go your own way rather than act by the rules?"), and the four highest loading items of the reverse-scored Lie scale were strong markers of the BU component of interpersonal exploitativeness (highest loading item: "Have you ever taken advantage of someone?").

As expected, all three BU scales were significantly associated witn nisk for AU (correlations or .sU tor Novelty Seeking, .22 for Psychoticism, and .34 for reverse-scored Lie); the correlations of Novelty Seeking and Lie with $\mathrm{AD}$ were significantly larger than the correlation of Psychoticism with $\mathrm{AD}, \chi^{2}(1)>6.89, p<.01$. The genetic correlations between the $\mathrm{BU}$ scales and $\mathrm{AD}$ were .59 (95\% CI $=.47-.71)$ for Novelty Seeking, .29 (95\% CI $=.14-.43)$ for Psychoticism, and $.48(95 \% \mathrm{CI}=.37-.59)$ for reverse-scored Lie, suggesting that genetic influences contributing to variation in Novelty Seeking, Psychoticism, and Lie scale scores accounted for $35 \%, 8 \%$, and $23 \%$, respectively, of genetic susceptibility for AD. Novelty Seeking and Lie scores contributed incremental genetic variation in $\mathrm{AD}$ over and above that accounted for by the other two scales, but no incremental variation was contributed by Psychoticism.

Similarly, all three BU scales were significantly associated with risk for CD (correlations of .34 for Novelty Seeking, .26 for Psychoticism, and .44 for reverse-scored Lie); the correlation of Lie with CD was significantly larger than the correlation of Novelty Seeking with $\mathrm{CD}, \chi^{2}(1)=11.64, p<.001$, which was significantly larger than the correlation of Psychoticism with $C D$, $\chi^{2}(1)=5.81, p=.016$. The genetic correlations between the $\mathrm{BU}$ scales and CD were $.56(95 \% \mathrm{CI}=.41-.71)$ for Novelty Seeking, $.41(95 \% \mathrm{CI}=.26-.56)$ for Psychoticism, and .55 (95\% $\mathrm{CI}=$ .43-.66) for reverse-scored Lie, suggesting that genetic influences contubuting to vartation in Novelty seeking, rsychoticism, and Lie scale scores accounted for $31 \%, 17 \%$, and $30 \%$, respectively, of genetic susceptibility for CD. All three BU scales contributed incremental genetic variation in CD over and above that accounted for by the other two scales.
All three BU scales accounted for a significant percentage of the genetic covariation between $\mathrm{AD}$ and $\mathrm{CD}$; Novelty Seeking, Psychoticism, and Lie accounted for $62 \%(95 \% \mathrm{CI}=43 \%-88 \%)$, $30 \%(95 \% \mathrm{CI}=14 \%-55 \%)$, and $59 \%(95 \% \mathrm{CI}=42 \%-82 \%)$ of the genetic covariation between $\mathrm{AD}$ and $\mathrm{CD}$, respectively. Novelty Seeking, $\chi^{2}(1)=23.40, p<.001$, and Lie, $\chi^{2}(1)=5.86, p=.015$, contributed incremental genetic covariation over and above that accounted for by the other two scales, but Psychoticism did not, $\chi^{2}(1)=0.65, p=.420$.

\section{Discussion}

In a community-based sample of 3,383 adult Australian twin pairs, genetic influences on personality dimensions accounted for a substantial proportion of the genetic diathesis for AD. Although our results are not surprising given the consistency of the indirect evidence from previous research, this study is the first to directly examine and quantify the extent to which personality dimensions share genetic risk factors with $\mathrm{AD}$.

\section{$B U$ and Genetic Risk for $A D$}

As expected, BU was the personality dimension that was most strongly associated with $\mathrm{AD}$. Although the contribution of $\mathrm{BU}$ to $\mathrm{AD}$ risk could be minimized by noting that it accounted for only $16 \%$ of the overall variation, the contribution of $\mathrm{BU}$ to $\mathrm{AD}$ risk was of greater significance when considered from a genetic perspective. In the present study, BU accounted for about $40 \%$ of the genetic variation in $\mathrm{AD}$ risk. In particular, the $\mathrm{BU}$ components of impulsivity (as measured by the TPQ Novelty Seeking scale) and interpersonal exploitativeness (as measured by the reversed EPQ-R Lie scale) each accounted for unique genetic variation in $A D$ risk. The results of the present study, considered in the context of the cumulative evidence from longitudinal studies linking earlier BU with later AD (Caspi et al., 1997; Cloninger et al., 1988; Loper et al., 1973; Zucker \& Lisansky Gomberg, 1986) and studies of offspring of alcoholics identifying elevations in BU among individuals at risk for AD (e.g., Finn et al., 2000; Sher at al., 1991), provide further support for the theory that the genetic diathesis for AD is partially mediated by the personality dimension of BU (Cloninger, 198/a; 1 arter, 1988; Iarter et al., 1985; Zuckerman, 1987). Several mechanisms have been advanced to explain the causal link between genetically influenced variation in BU and future AD (Sher et al., 1999). For example, higher levels of BU may indirectly influence $\mathrm{AD}$ risk via the social milieu by leading 
to association with deviant heavy-drinking peers (Martin, Lynch, Pollock, \& Clark, 2000; Sher et al., 1999), and higher levels of BU may also influence AD risk more directly by leading to impaired decisions about drinking (Martin et al., 2000; Sher et al., 1999) and an inability to inhibit alcohol seeking even in the presence of negative consequences (Martin et al., 2000).

There are also several noncausal explanations consistent with the results of the present study. Traits that are associated with genetic variation in $\mathrm{AD}$ risk might merely represent alternate manifestations or different developmental stages of the same underlying disorder. Although this is a reasonable explanation for the genetic association of $A D$ with $C D$, and even of $A D$ with the reversed EPQ-R Lie scale (which might be considered an indicator of mild antisocial tendencies), it cannot easily explain the genetic association of AD with TPQ Novelty Seeking, which is a purer measure of personality distinct from "the behavior of the addict" (Nathan, 1988). Another explanation is that there are one or more genes that have pleiotropic effects on a range of traits, including $\mathrm{AD}, \mathrm{CD}$, and the personality dimension of $\mathrm{BU}$, possibly through their effect on common underlying psychobiological processes. Regardless of whether the genetic association between $\mathrm{BU}$ and $\mathrm{AD}$ is causal or noncausal, the results of the present study clearly suggest that a potentially fruitful strategy for discovering susceptibility genes for $\mathrm{AD}$ will be to identify genes that are associated with individual differences in BU-related traits such as impulsivity.

\section{$N E$ and Genetic Risk for $A D$}

Previous research has been inconsistent concerning the role of $\mathrm{NE}$ in the etiology of $\mathrm{AD}$. One research design issue that may affect the magnitude of the association of NE with $\mathrm{AD}$ is whether $\mathrm{NE}$ is measured contemporaneously with an active episode of $\mathrm{AD}$. It has long been argued that elevated levels of NE among individuals with $\mathrm{AD}$ relative to controls are more likely to be a consequence of $\mathrm{AD}$ than a cause (Schuckit, 1986). If $\mathrm{AD}$ is a cause of elevated levels of $\mathrm{NE}$, then remission of $\mathrm{AD}$ may be followed by reductions in levels of NE (Pettinati, Sugarman, \& Maurer, 1982). In other words, $\mathrm{NE}$ may be a correlate of "statelike" aspects of $\mathrm{AD}$ rather than the underlying "traitlike" risk for $\mathrm{AD}$. In the present study, we minimized the possibility of discovering personality correlates of "statelike" aspects of $\mathrm{AD}$ by focusing on lifetime assessments of $\mathrm{AD}$ and by assessing personality dimensions and $\mathrm{AD}$ at different measurement occasions 4 years apart. The association between NE and AD that we obtained was much weaker than the association between $\mathrm{BU}$ and $\mathrm{AD}$. Nonetheless, NE accounted for a significant albeit modest $4 \%$ of the genetic variation in $\mathrm{AD}$ risk among men.

Another possible explanation for the inconsistent findings on the association between $\mathrm{NE}$ and $\mathrm{AD}$ is the extent to which the measure of NE used assesses the traits of hostility, anger, aggression, or impulsivity. For example, in the three-factor model of Tellegen (1982), aggression is included under the higher order dimension of $\mathrm{NE}$, and aggression is more strongly associated with $\mathrm{AD}$ than are the other components of NE (Caspi et al., 1997; McGue et al., 1997). Similarly, hostility and impulsivity are included under the higher order dimension of neuroticism in the NEO Personality Inventory (Costa \& McCrae, 1992). When interpreting studies of the association of NE with $\mathrm{AD}$, it is important to take into con- sideration the particular measure of NE that has been used; it is likely that measures that include hostility, anger, aggression, or impulsivity will yield a stronger association than studies that use narrower measures of NE. In the present study, items tapping hostility, anger, aggression, and impulsivity were subsumed under the higher order dimension of BU (although our measure of BU contained few hostility, anger, or physical aggression items) and not under the higher order dimension of $\mathrm{NE}$.

\section{$P E$ and Genetic Risk for $A D$}

Previous research has been even more inconsistent concerning the role of $\mathrm{PE}$ in the etiology of $\mathrm{AD}$, in that studies have failed to detect an association between PE and AD (McGue et al., 1997), have shown a positive association between $\mathrm{PE}$ and $\mathrm{AD}$ (Sher, Bartholow, \& Wood, 2000; Prescott, Neale, Corey, \& Kendler, 1997, obtained a positive association between extraversion and problem drinking), and have shown a negative association between PE and AD (Caspi et al., 1997). Sher et al. (1999) suggested three explanations for these disparate results. First, extraversion/sociability may be positively related to problem drinking but inversely related to more severe levels of AD. Second, PE may be more strongly associated with $\mathrm{AD}$ among women than among men. Third, traits subsumed under the category of PE may be more accurately conceptualized as reflecting aspects of BU. The present study did not address the first explanation, but our results are consistent with the latter two. The correlation between PE and AD was significantly larger among women than among men, and the genetic association between $\mathrm{PE}$ and $\mathrm{AD}$ was no longer significant after accounung for geneuc variation attributable to BU. I nus, the association between $\mathrm{PE}$ and $\mathrm{AD}$ may be dependent on the measure of $P E$ used, with studies using measures that emphasize liveliness (such as the EPQ-R [Eysenck et al., 1985] and the NEO Personality Inventory [Costa \& McCrae, 1992]) and excitement seeking (such as the NEO Personality Inventory [Costa \& McCrae, 1992]) being more likely to find positive associations than those using measures that do not emphasize these components (such as the Multidimensional Personality Questionnaire; Tellegen, 1982).

\section{Sex Differences and Genetic Risk for AD}

The results of this study suggest that there are more similarities than differences in the inheritance of $\mathrm{AD}$ among men versus women. We confirmed our previous finding from this sample that $\mathrm{AD}$ is equally heritable among men and women (Heath, Bucholz, et al., 1997), which is consistent with the results of our reanalyses of earlier studies examining sex differences in the heritability of AD (Heath, Slutske, \& Madden, 1997). AD risk was equally correlated with BU in men and women, and the personality dimension accounting for the largest proportion of genetic variation in AD risk for both men and women was BU. Clearly, these results are contradictory to the widespread notions (e.g., Cloninger, 1987a) that $A D$ is less heritable among women than among men and that $\mathrm{AD}$ is primarily associated with NE among women and $\mathrm{BU}$ among men. In fact, NE accounted for a portion of the genetic risk for $\mathrm{AD}$ among men but not among women, and $\mathrm{BU}$ accounted for significantly more of the genetic risk for $\mathrm{AD}$ among women than among men. 


\section{Personality and Common Genetic Risk for $A D$ and $C D$}

Risk factors for psychopathology can be classified according to whether they increase the risk for psychopathology in general ("common risk factors"), increase the risk for a class of similar disorders ("broadband-specific risk factors"), or increase the risk for a single disorder ("narrowband-specific risk factors"; Garber \& Hollon, 1991; Weiss, Susser, \& Catron, 1998). The extent of co-occurrence between psychiatric disorders can be explained by the extent to which they share common or broadband-specific risk factors. Recent twin research suggests that genetic risk factors are, in many cases, the predominant cause of co-occurrence of psychiatric disorders (e.g., Kendler et al., 1995; Slutske et al., 2000). Therefore, genetic research will be especially important in identifying the common and broadband-specific risk factors for psychopathology and for understanding the mechanisms underlying the comorbidity between psychiatric disorders. The present study represents a first step by demonstrating that genetically influenced dimensions of personality such as BU may explain much of the genetic basis of the greater-than-chance co-occurrence of AD and CD. Although personality may contribute only modestly to any single psychiatric disorder, it may be the predominant contributor to the comorbidity between psychiatric disorders.

\section{Specific Genetic Risk for $A D$}

The analyses presented here have demonstrated a strong genetic correlation between $\mathrm{BU}$ and $\mathrm{AD}$ risk, but they also indicate that a substantial proportion of the total genetic variation in $\mathrm{AD}$ risk is not accounted for by such personality factors (Heath, Slutske, \& Madden, 1997); we estimated that $60 \%(95 \% \mathrm{CI}=46 \%-72 \%)$ of the genetic variation in $\mathrm{AD}$ risk for men and women could not be accounted for by genetic variation in the personality dimensions included in the present study. Genetically determined differences in level of response to alcohol (e.g., subjective intoxication or static ataxia after a standardized dose of alcohol; Schuckit \& Smith, 1996) appear to account for additional genetic variation (Heath et al., 1999, 2001). In the future, better characterization of the interactive effects of personality differences and differential reactions to alcohol may further enhance our understanding of the role of personality differences and other genetic risk factors in the development of $\mathrm{AD}$.

\section{Limitations}

The present study should be interpreted in light of two main limitations that may have affected the results. First, the sample involved members of a volunteer twin registry, probably underrepresenting those with a history of severe or persisting $A D$ or antisocial behavior. Second, the data were cross-sectional, and both lifetime $\mathrm{AD}$ and $\mathrm{CD}$ diagnoses were based on retrospective reports. The advantage of the retrospective method used in the present cross-sectional study is that the associations among AD, $\mathrm{CD}$, and dimensions of personality could be examined in a sample nearly through the age of risk for both disorders. A major disadvantage is that it precluded our ability to examine potentially important developmental changes in mediation of the relationships among $\mathrm{AD}, \mathrm{CD}$, and dimensions of personality or to assess whether different dimensions of personality might explain genetic variation in earlier- versus later-onset $A D$. These developmental questions remain to be addressed in future prospective twin studies.

\section{References}

American Psychiatric Association. (1987). Diagnostic and statistical manual of mental disorders (3rd ed., rev.). Washington, DC: Author.

Bucholz, K. K., Cadoret, R., Cloninger, C. R., Dinwiddie, S. H., Hesselbrock, V. M., Nurnberger, J. I., Jr., Reich, T., Schmidt, I., \& Schuckit, M. A. (1994). A new semi-structured psychiatric interview for use in genetic linkage studies: A report on the reliability of the SSAGA. Journal of Studies on Alcohol, 55, 149-158.

Carey, G., \& DiLalla, D. L. (1994). Personality and psychopathology: Genetic perspectives. Journal of Abnormal Psychology, 103, 32-43.

Caspi, A., Begg, D., Dickson, N., Harrington, H. -L., Langley, J., Moffitt, T. E., \& Silva, P. A. (1997). Personality differences predict health-risk behaviors in adulthood: Evidence from a longitudinal study. Journal of Personality and Social Psychology, 73, 1052-1063.

Cloninger, C. R. (1987a). Neurogenetic adaptive mechanisms in alcoholism. Science, 236, 410-416.

Cloninger, C. R. (1987b). A systematic method for clinical description and classification of personality variants: A proposal. Archives of General Psychiatry, 44, 573-588.

Cloninger, C. R., Przybeck, T. R., \& Svrakic, D. M. (1991). The Tridimensional Personality Questionnaire: U.S. normative data. Psychological Reports, 69, 1047-1057.

Cloninger, C. R., Sigvardsson, S., \& Bohman, M. (1988). Childhood personality predicts alcohol abuse in young adults. Alcoholism: Clinical and Experimental Research, 12, 494-505.

Costa, P. T., Jr., \& McCrae, R. R. (1992). Revised NEO Personality Inventory (NEO-PI-R) and NEO Five Factor Inventory (NEO-FFI) professional manual. Odessa, FL: Psychological Assessment Resources.

Duffy, D. L. (1994). Asthma and allergic diseases in Australian twins and their families. Unpublished doctoral dissertation, Queensland University, Brisbane, Queensland, Australia.

Eaves, L. J., Eysenck, H. J., \& Martin, N. G. (1989). Genes, culture and personality: An empirical approach. New York: Academic Press.

Eysenck, H. J., Eysenck, S. B. G., \& Barrett, P. (1985). A revised version of the Psychoticism scale. Personality and Individual Differences, 6 , 21-29.

Finn, P. R., Sharkansky, E. J., Brandt, K. M., \& Turcotte, N. (2000). The effects of familial risk, personality, and expectancies on alcohol use and abuse. Journal of Abnormal Psychology, 109, 122-133.

Garber, J., \& Hollon, S. D. (1991). What can specificity designs say about causality in psychopathology research? Psychological Bulletin, 110, 129-136.

Heath, A. C., Bucholz, K. K., Madden, P. A. F., Dinwiddie, S. H., Slutske, W. S., Bierut, L. J., Statham, D. J., Dunne, M. P., Whitfield, J., \& Martin, N. G. (1997). Genetic and environmental contributions to alcohol dependence risk in a national twin sample: Consistency of findings in women and men. Psychological Medicine, 27, 1381-1396.

Heath, A. C., Cloninger, C. R., \& Martin, N. G. (1994). Testing a model for the renetic structure of personality: A comparison of the personality systems of Cloninger and Eysenck. Journal of Personality and Social Psychology, 66, 762-775.

Heath, A. C., Madden, P. A. F, Bucholz, K. K., Bierut, L. J., Whitfield, J. B., Dinwiddie, S. H., Slutske, W. S., Statham, D. J., \& Martin, N. G. (2001). Towardo a molooular opidomiology of aloohol dopondonoe: Analyzing the interplay of genetic and environmental risk-factors. British Journal of Psychiatry, 178(Suppl. 40), S33-\$40.

Heath, A. C., Madden, P. A. F., Bucholz, K. K., Dinwiddie, S. H., Slutske, W. S., Bierut, L. J., Rohrbaugh, J. W., Statham, D. J., Dunne, M. P., Whitfield, J. B., \& Martin, N. G. (1999). Genetic differences in alcohol 
sensitivity and the inheritance of alcoholism risk. Psychological Medicine, 29, 1069-1081.

Heath, A. C., Slutske, W. S., \& Madden, P. A. F. (1997). Gender differences in the genetic contribution to alcoholism risk and to alcohol consumption patterns. In R. W. Wilsnack \& S. C. Wilsnack (Eds.), Gender and alcohol (pp. 114-149). New Brunswick, NJ: Rutgers University Press.

Jardine, R., \& Martin, N. G. (1984). Causes of variation in drinking habits in a large twin sample. Acta Geneticae Medicae et Gemellologicae, 33, 435-450.

Jöreskog, K. G., \& Sörbom, D. (1996). PRELIS 2: User's reference guide. Chicago: Scientific Software International.

Kendler, K. S., Walters, E. E., Neale, M. C., Kessler, R. C., Heath, A. C., \& Eaves, L. J. (1995). The structure of the genetic and environmental risk factors for six major psychiatric disorders in women: Phobia, generalized anxiety disorder, panic disorder, bulimia, major depression, and alcoholism. Archives of General Psychiatry, 52, 374-383.

Krueger, R. F., Caspi, A., \& Moffitt, T. E. (2000). Epidemiological personology: The unifying role of personality in population-based research on problem behaviors. Journal of Personality, 68, 967-998.

Little, R. J. A., \& Rubin, D. B. (1987). Statistical analysis with missing data. New York: Wiley.

Loehlin, J. C. (1992). Genes and environment in personality development. Newbury Park, CA: Sage.

Loehlin, J. C. (1996). The Cholesky approach: A cautionary note. Behavior Genetics, 26, 65-69.

Loper, R. G., Kammeier, M. I., \& Hoffman, H. (1973). MMPI characteristics of college freshman males who later became alcoholics. Journal of Abnormal Psychology, 82, 159-162.

Martin, C. S., Lynch, K. G., Pollock, N. K., \& Clark, D. B. (2000). Gender differences and similarities in the personality correlates of adolescent alcohol problems. Psychology of Addictive Behaviors, 14, 121-133.

Mrfine M. Slutske. W. Taylnr. I T \& Iarnnn, W f (1007) Derennality and substance use disorders: I. Effects of gender and alcoholism subtype. Alcoholism: Clinical and Experimental Research, 21, 513-520.

Nathan, P. E. (1988). The addictive personality is the behavior of the addict. Journal of Consulting and Clinical Psychology, 56, 183-188.

Neale, M. C., Boker, S. M., Xie, G., \& Maes, H. H. (1999). Mx: Statistical modeling (5th ed.). Richmond: Department of Psychiatry, Medical College of Virginia.

Neale, M. C., \& Cardon, L. R. (1992). Methodology for genetic studies of twins and families. Dordrecht, the Netherlands: Kluwer Academic.

Pettinati, H. M., Sugarman, A., \& Maurer, H. S. (1982). Four-year MMPI changes in abstinent and drinking alcoholics. Alcoholism: Clinical and Experimental Research, 6, 487-494.

Prescott, C. A., Neale, M. C., Corey, L. A., \& Kendler, K. S. (1997). Predictors of problem drinking and alcohol dependence in a populationbased sample of female twins. Journal of Studies on Alcohol, 58, 167-181.

Schuckit, M. A. (1986). Genetic and clinical implications of alcoholism and affective disorder. American Journal of Psychiatry, 143, 140-147.

Schuckit, M. A., \& Smith, T. L. (1996). An 8-year follow-up of 450 sons of alcoholic and control subjects. Archives of General Psychiatry, 53 , 202-210.

Sher, K. J. (1991). Children of alcoholics: A critical appraisal of theory and research. Chicago: University of Chicago Press.
Sher, K. J., Bartholow, B. D., \& Wood, M. D. (2000). Personality and substance use disorders: A prospective study. Journal of Consulting and Clinical Psychology, 68, 818-829.

Sher, K. J., \& Trull, T. J. (1994). Personality and disinhibitory psychopathology: Alcoholism and antisocial personality disorder. Journal of Abnormal Psychology, 103, 92-102.

Sher, K. J., Trull, T. J., Bartholow, B. D., \& Vieth, A. (1999). Personality and alcoholism: Issues, methods, and etiological processes. In $\mathrm{K}$. E. Leonard \& H. T. Blane (Eds.), Psychological theories of drinking and alcoholism (pp. 54-105). New York: Guilford Press.

Sher, K. J., Walitzer, K. S., Wood, P. K., \& Brent, E. E. (1991). Characteristics of children of alcoholics: Putative risk factors, substance use and abuse, and psychopathology. Journal of Abnormal Psychology, 100, 427-448.

Slutske, W. S., Eisen, S. A., True, W. R., Lyons, M. J., Goldberg, J., \& Tsuang, M. T. (2000). Common genetic vulnerability for pathological gambling and alcohol dependence in men. Archives of General Psychiatry, 57, 666-673.

Slutske, W. S., Heath, A. C., Dinwiddie, S. H., Madden, P. A. F., Bucholz, K. K., Dunne, M. P., Statham, D. J., \& Martin, N. G. (1997). Modeling genetic and environmental influences in the etiology of conduct disorder: A study of 2,682 adult twin pairs. Journal of Abnormal Psychology, 106, 266-279.

Slutske, W. S., Heath, A. C., Dinwiddie, S. H., Madden, P. A. F., Bucholz, K. K., Dunne, M. P., Statham, D. J., \& Martin, N. G. (1998). Common genetic risk factors for conduct disorder and alcohol dependence. Journal of Abnormal Psychology, 107, 363-374.

Tarter, R. E. (1988). Are there inherited behavioral traits that predispose to substance abuse? Journal of Consulting and Clinical Psychology, 56, 189-196.

Tarter, R. E., Alterman, A. I., \& Edwards, K. L. (1985). Vulnerability to alcoholism in men: A behavior-genetic perspective. Journal of Studies on Alcohol. 46. 329-356.

Tellegen, A. (1982). Brief manual of the Multidimensional Personality Questionnaire. Unpublished manuscript.

Weiss, B., Susser, K., \& Catron, T. (1998). Common and specific features of childhood psychopathology. Journal of Abnormal Psychology, 107, 118-127.

Zucker, R. A., \& Lisansky Gomberg, E. (1986). Etiology of alcoholism reconsidered: The case for a biopsychosocial process. American Psychologist, 41, 783-793.

Zuckerman, M. (1987). Is sensation seeking a predisposing trait for alcoholism? In E. Gottheil, K. A. Druley, S. Pashko, \& S. P. Weinstein (Eds.), Stress and addiction (pp. 283-301). New York: Brunner/Mazel.

Zuckerman, M., Kuhlman, D. M., \& Camac, C. (1988). What lies beyond $\mathrm{E}$ and $\mathrm{N}$ ? Factor analyses of scales believed to measure basic dimensions of personality. Journal of Personality and Social Psychology, 54, 96107.

Zuckerman, M., Kuhlman, D. M., Joireman, J., Teta, P., \& Kraft, M. (1993). A comparison of three structural models for personality: The Big Three, the Big Five, and the Alternative Five. Journal of Personality and Social Psychology, 65, 757-768.

Received August 22, 2000

Revision received June 21, 2001

Accepted June 27, 2001 